\title{
Integration of Tactical Aspects into Strategic Production Network Planning
}

\author{
Elias Auberger*, Christian Ramsauer
}

\begin{abstract}
Nowadays, production companies are facing an increasingly volatile environment. Due to increasing globalization, but also de-globalization, taking into consideration an internal production network is becoming more and more important for companies, all in order to be able to counteract in an agile way the uncertainties such as swings in the demand. Current production network planning procedures focus on (re-)locating decisions without delving into what happens inside the plants, neglecting the dynamics of production networks, following a rigid top-down approach during the configuration phase, and they do not integrate the effects of planning tasks at the factory level (tactical and operational planning). In order to be able to make strategic decisions with a well-founded database regarding the production network, the effects on the tactical and operational level must be considered in an iterative way during the strategic decision-making process. The aim of this research is to define the requirements for an approach to strategic production network planning, which considers the effects at the tactical and operational level in an iterative way, and to develop a process model, derived from the requirements, that in its five phases considers the deficiencies of the existing approaches.
\end{abstract}

Keywords: decision-making; factory planning; production network planning; strategic planning; tactical planning

\section{INTRODUCTION}

Today's industry is strongly influenced by a globalisation process that has lasted for several years. In recent years, large companies have been expanding their production networks according to strategic market exploitation and cost related decisions [1]. Such decision-making over longer periods leads to historically grown production networks that usually operate at low efficiency levels. Therefore, these networks include a high potential for efficiency improvement potentials, where cost savings of up to $45 \%$ can be achieved $[2,3]$.

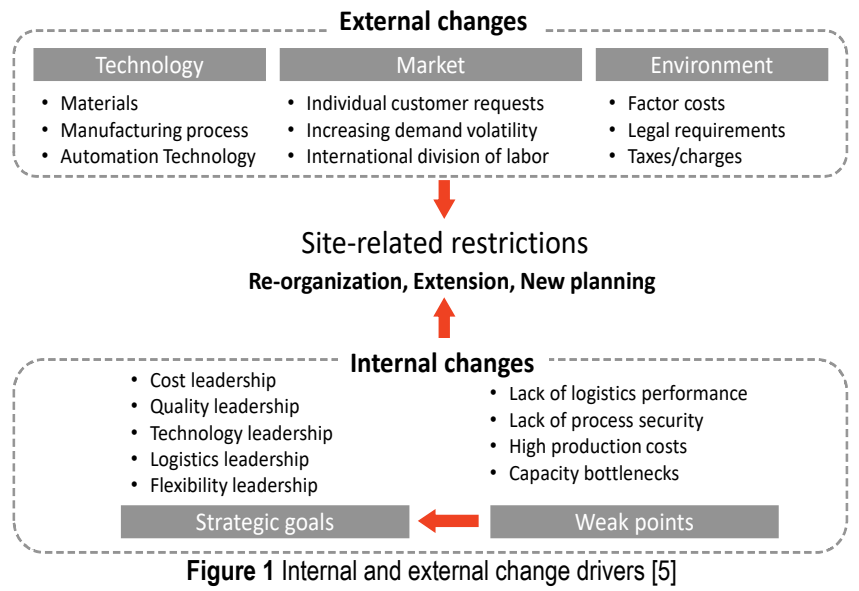

Because most production networks have grown historically, e.g. through merge and acquisition activities, companies are very susceptible to internal and external uncertainties [1, 3]. Three major change drivers can summarize external uncertainties: (1) technology, (2) market and (3) environment, e.g. tax regulations or factor costs. Furthermore, the so-called black swan events, such as the Covid-19 crisis in 2020, can suddenly occur [4]. Internal changes can occur due to the identification of current challenges of internal processes, as well as due to the changes in strategic goals [5].
After the identification of challenges resulting from external or internal changes, the production network and the factories within this network have to be adapted in order to accordingly keep and/or enhance productivity/efficiency [1]. Re-planning due to the above-mentioned triggers can provide an opportunity for the management to coordinate the factory and network interrelations from a strategic and tactical point of view. The basis is to identify the interactions between the factory and the production network level and to use potentials to achieve a robust and agile overall system to cope with future uncertainties. In practice, the planning and implementation of the changes and the adaption of specific factories are based either on long-term project approaches or on individual, often locally isolated changes or investment decision at the factory level. This current approach involves major challenges of dealing on the one hand with a huge amount of interdependencies in networks, and on the other hand, of having to continuously improve isolated factories and conduct local investments without knowing its impact on the network level [6].

The goal of this research is to develop a proposal for a process model for the planning of production networks by integrating tactical/operational planning into the strategic decision-making process. Therefore, as the first step, an overview of production networks is provided. Afterwards, the problem of decision-making during the configuration process of production networks is discussed in more detail. To complete the planning process sequence on the factory level, goals and tasks of factory planning are briefly discussed upon. Derived from the decision theory, requirements for the configuration of production networks are defined, which are needed to include the tactical/operational view in strategic decision-making. Subsequently, common methods for the configuration of production networks are examined on the basis of a literature analysis and discussed according to the defined requirements for decision-making and the capability for the integration of the tactical/operational factory level in the process. As the last step, a proposal for a process model is outlined, which integrates the tactical/operational view in an iterative manner 
into the strategic decision-making process during production network planning.

\section{CURRENT STATE OF RESEARCH}

In this chapter, a classification of different kinds of production networks is given. Subsequently, the challenges occurring during the production network planning procedure are presented, and the requirements according to the decision-making process are defined. The second part describes the goals and tasks of the factory planning process. At the end of this chapter, the derived requirements for a production network planning approach are described.

\subsection{Production Network Planning}

Production networks are networks in a corporate environment which are connected through the production of products and services by using specific resources and competencies of the partners involved [7]. Production networks (level 1) are characterized by relationships in terms of performance and supply between different production locations of a company [8]. The linked site location (level 2) describes the geographical distribution of a company's production sites, including the long-term allocation of services and resources or operating equipment to these sites [9]. On closer examination, the term linked site location can be used as a synonym for the term production network, as large overlaps become apparent [10].

According to Rudberg and Olhager, a network can be structured from the perspective of supply chain management and production management. From the supply chain management's point of view, the focus is on the structure of sites owned by different organizations. From the point of view of the production management, mainly internal networks are considered, which are completely owned by a company [11].

For the classification and differentiation of both points of views on production networks, the two dimensions of "number of organisations in the network" and "number of sites per organisation" can be used (see Fig. 2) [11].

\begin{tabular}{|c|c|c|}
\hline \multirow{2}{*}{$\begin{array}{l}\text { Number of } \\
\text { organizations } \\
\text { in network } \\
\text { Single }\end{array}$} & $\begin{array}{l}\text { Supply Chain } \\
\text { (multi-organization, single-site) }\end{array}$ & $\begin{array}{l}\text { Inter-firm network } \\
\text { (multi-organization, multi-site) }\end{array}$ \\
\hline & $\begin{array}{c}\text { Plant } \\
\text { (single-organization, single-site) }\end{array}$ & $\begin{array}{l}\text { Intra-firm network } \\
\text { (single-organization, multi-site) }\end{array}$ \\
\hline & Number of site & er organization \\
\hline
\end{tabular}

As it has already been mentioned, linked sites represent a production network. The spatial view of a company can be, according to Wiendahl, divided into six levels [5] (see Fig. 3): production network (level 1), linked site location (level 2), general structure (level 3), buildings (level 4), work areas (level 5) and work station (level 6). According to WIENDAHL, the planning of a production network and site location is a strategic task. Strategic planning covers a longterm period of several years and is carried out by the upper management of companies. Tactical and operational planning, on the other hand, have a lower period and they focus on the lower planning levels, from general structural planning to the planning of buildings, areas and workplaces, and they are assigned to factory planning tasks. [12]

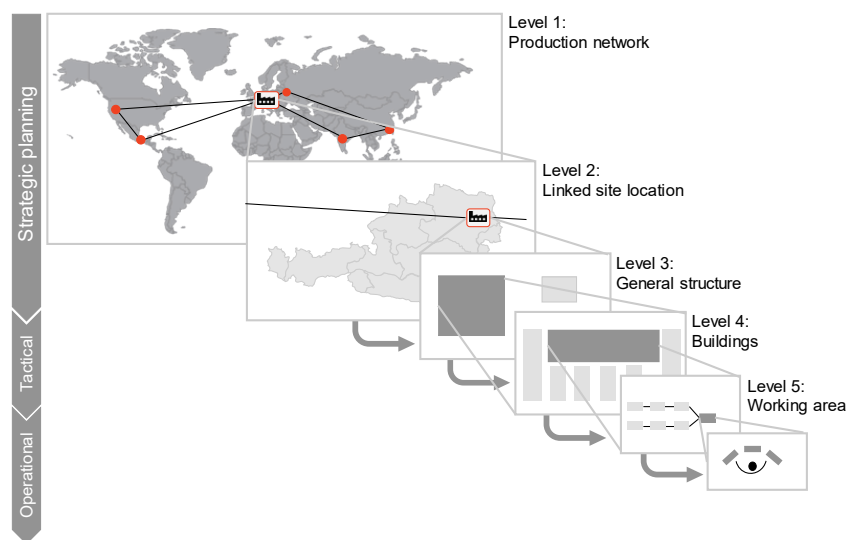

Figure 3 Spatical view of a company [5]

Strategic planning (level 1 and level 2) deals with longterm behavioural principles or measures to achieve long-term goals and is triggered by the corporate strategy [13]. The production strategy is to be understood as a part of the corporate strategy, which serves to make production decisions in terms of high-level goals [14]. Their formulation defines the objectives in which direction production capabilities should be developed in order to contribute to the competitiveness of the company [15]. Among the most common factors that production should strive for are the factors' cost, quality and delivery reliability. In the context of networks, these can be expanded with the terms flexibility, innovation and speed of delivery. [16] According to PAWELLEK, the production strategy is strongly influenced by external changes. These changes can come from the market, environment or technology [17]. If a company produces at several locations, managers are confronted with three central questions [18]:

- Is the company producing (and sourcing) their products at the right places?

- Does each production site have required resources to do what is expected of it?

- How does the company transfer know-how among production sites and how does it improve their operations?

Confronted with those questions, managers have to make decisions according the production network. In the decisionmaking theory, the term decision is used more broadly and it includes in general all acts of selecting one of several alternatives of action. [19] There are different types of decisions; but in the business context, strategic, tactical or operational decisions, as well as vary by value-at-stake and frequency decisions are considered as the most important [20]. Depending on how predictable the future is, decisions 
have to be made under certainty, under risk, and under uncertainty [21].

As it has already been mentioned, production networks are nowadays usually historically grown and are rarely the result of long-term strategic planning [12]. The reason for the lack of strategic orientation of the existing networks is to be found in the deficiencies in network configuration, which result from two main challenges associated with the network planning process. According to Mauerer et al., the process of realignment is complex and politically difficult [22]. SCHUH et al. demonstrated the complexity and size of the solution space, as well as the limited time available for decisionmakers for the selection of a network alternative [23]. These two aspects summarize the analytical and procedural complexity during the network configuration process. The analytical complexity describes the factors that determine the logical penetration and evaluation of a production network and the available options for action within the situation. Process complexity, on the other hand, entails challenges in terms of the process steps that are necessary to come up with a decision for an alternative solution that is required within a company. [24]

In the past, many authors developed approaches for the decision-making process. Furthermore, the approaches differ in the number of different phases and common steps in different process can be derived, as shown in Fig. 4. [25]

\begin{tabular}{|c|c|c|c|c|}
\hline Initiation phase & & & & on \\
\hline $\begin{array}{l}\text { Describe initial } \\
\text { situation } \\
\text { Define scope, } \\
\text { objectives and } \\
\text { evaluation } \\
\text { method }\end{array}$ & $\begin{array}{l}\text { Derive and gather } \\
\text { required } \\
\text { information }\end{array}$ & $\begin{array}{l}\text { Create data based } \\
\text { decision model } \\
\text { Create model based } \\
\text { variants }\end{array}$ & Evaluate Data & $\begin{array}{c}\text { Make decision } \\
\text { based on } \\
\text { evaluation }\end{array}$ \\
\hline
\end{tabular}

Figure 4 Decision-making process [25]

Many authors add the realisation or implementation as the sixth phase in the decision-making process. It is important to note that the pure sequence of the shown steps does not express a rigid sequence that has to be passed through linearly from the beginning to the end in the decision-making process. If, in the course of problem processing, findings arise that should be taken into account in subtasks that have already been finished, these results should be considered in the sense of a feedback loop in the process [26].

In his research, Ferdows describes one main challenge of current procedures by explaining that in most companies, production network improvements are a result of many individual, incremental decisions which are based on intensive cost-benefit analyses. However, decision makers neglect the holistic, unintended consequences of an incremental improvement decision on a network level. On the other hand, the stronger the focus on an individual decision, the less consideration is given to the effects on the long-term strategy and the overall picture [27].

It can be summarized that production network planning is a complex task, which is triggered by different events. Derived from the goals of the corporate strategy, decisionmakers are confronted with multiple alternatives. The limited time available to the decision-makers for the selection of a network alternative results in a poorly founded decision. Furthermore, as external changes constantly occur, the adaption of the production network is an ongoing planning task and an elaborated database should be used in multiple future situations.

As it has already been mentioned, in addition to external change drivers, internal changes can also lead to changes in the strategic goals and trigger a restructuring of the production network and the subsequent tactical and operational planning of tasks at a factory level. The next chapter describes the main goals, tasks and process steps of common planning procedures at the factory level.

\subsection{Factory Planning}

If the network planning process results in the need for adaptation on the factory level, concrete measures must be developed and evaluated [28]. Various types of factory planning exist in literature, e.g. rescheduling, relocation, adaptation planning or reengineering of factories. The main goal of factory planning is the development of sustainable solution concepts for the future factory. Derived from the main goal mentioned above, the quality of these solution concepts is measured, among other things, by the fulfilment of individual objectives such as profitability, product and process quality, flexibility and adaptability [5].

With the permanent pursuit of these goals, factory planning is assigned a variety of tasks, which generally include both strategic projects (e.g. production planning and technology development strategies), as well as structural (e.g. location/building structure, production organisation) and system projects (e.g. processing/transport systems). In classical factory planning, for example, the first step is to define the goals for the planning procedure, which are usually derived from strategic specifications and requirements. Furthermore, the actual state is then analysed. In subsequent structure planning, the future structure of a factory is to be designed in a way that it fulfils the previously defined strategic objectives. This includes, for example, the dimensioning of the required areas and the planning of the processes (e.g. flow of material and information), which links the individual steps of the value creation process [29].

During the structuring phase, the planned target state is always compared with the actual state, and the need for change is identified. It is not uncommon for adaptation planning to require further investment decisions in order to be able to meet the strategic objectives [6].

A study with industry experts who are holding a management position in the manufacturing industry in Germany pointed out that most investment decisions have been made solely from a local factory perspective, while the impacts on the network have not been considered [30]. CHENG also pointed out that there is still a lack of knowledge about the interactions between the individual plants and the impact of the changes of the processes there on the manufacturing network as a whole [31].

It can be seen in many industrial cases that planning projects not only identify the required adaptions and investments to meet the defined strategic goals, but also expose huge potentials for optimization in terms of resource utilization. This results in more efficient material flows and 
higher productivity of workers and machine utilizations. With the operational measures such as lean production, process or shop floor redesign potential savings of $10 \%-20 \%$ can be achieved [22].

In classic production network planning projects, decisions for specific goals for factories are a precondition at the starting point. Improvement potentials, which have been identified during the factory planning process, are not taken into account in the decision-making process on the strategic production network level anymore.

\subsection{Derived Requirements}

From the obtained characteristics of production networks and their planning, and the challenges during the decisionmaking process and the effects of planning tasks at the factory level, the following requirements for the production network planning process can be derived:

- Target derivation from the corporate strategy,

- Inclusion of multiple alternatives for decision-makers,

- Effort-oriented and practical modelling,

- Integration of the impacts of the tactical/operational

planning at the factory level,

- Iterative decision-making,

- Multiple usage by future changes,

- Adjustment to different decision situations.

\section{EXISTING MODELS FOR PRODUCTION NETWORK PLANNING}

In literature, various methods for the configuration of production networks are available. To structure them, Jacob and Ernst suggested a two-dimensional matrix (see Fig. 5), which clusters the existing models with consideration of the process-related complexity or analytical complexity $[12,32]$.

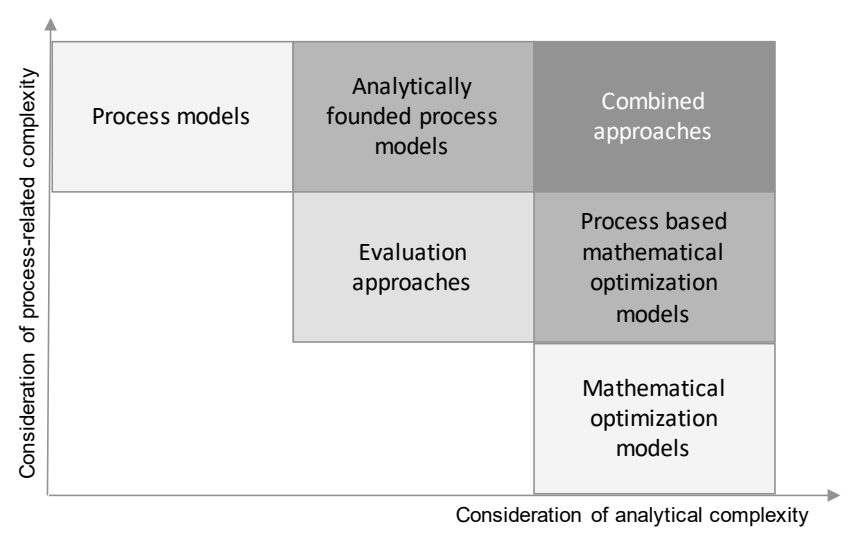

Figure 5 Clustering of the process and analytical models [12,32]

\subsection{Process Models}

According to Ernst, process models focus on the one hand on the description of temporal sequences and the explanation of the contents of individual phases, but neglect on the other hand the concrete identification and evaluation of network alternatives [12].
Christodolous et al. developed a process model for the configuration of production networks on the basis of four guiding questions and phases. The first phase deals with the necessity of the adaption of the production network. In the second phase, the topic of the adaptions needed for an excellent market position is defined. Afterwards, the third phase defines the optimal locations for different plants by defining the role and nature of different plants in the network. The last phase covers the topic of how to realize the adaption of the network [33]. One disadvantage of this process model is that it does not answer the question of how to identify attractive network options and alternatives. Furthermore, there is no guidance towards how to define strategic goals [24].

Justus developed a model which consists of five phases. In the first phase, the object under consideration is defined in the form of a product. Subsequently, measures are to be defined in a strategy audit, which contribute to the improvement of strategically important capabilities. The strategy audit is followed by an analysis of the required value-added activities. In the last phase, a network simulation is used to model and visualize complex interrelationships [8]. Disadvantages of this approach are that the output of the strategy audit are not concrete target values on which the development of network alternatives should be based on and that required changes at the plant level are not discussed.

\subsection{Mathematical Optimization Models}

Mathematical optimization models, which are used to calculate the optimal network configuration while neglecting any process-related requirements, represent the computerbased, analytical models. Due to the frequently omitted practical application of the models, deficits with regard to their suitability for practical use were mentioned in literature. [24]

Lanza \& Moser developed a multi-criteria optimization model which includes both the quantitative and qualitative target values. A hybrid approach is used to solve the model by using a reference point and the constraint method. For the consideration of the existing uncertainties in the context of network configuration, consistent future scenarios are determined. The optimization model is solved for each scenario and thus the necessity and the point of time for change under the consideration of multidimensional future uncertainties are defined. [34] The extensive modelling of relevant cost rates and the consideration of quantitative target values and multidimensional uncertainties are the key strengths. [24] One disadvantage of the model is that it seems to be very time demanding during data collection and does not integrate the impacts of tactical/operational planning at the factory level.

\subsection{Combined Approaches}

Approaches which include a process model and a mathematical optimization model and thus make a contribution to the mastery of both procedural and analytical complexity are called combined approaches [24]. 
In this model, Meyer introduced four phases which are the identification of the need for action and strategic goals, the modelling of the existing production, development of the strategic network concept, implementation and management of network adaptation [35]. For Meyer, the identification of the need for action is the starting point of network configuration. Five indicators are provided for this. The phase for the modelling of the existing production includes the data collection. For the development of the strategic network concept, Meyer introduces a two-stage procedure. First, a greenfield approach is used to identify an ideal network alternative. The iterative procedure consists of the definition of network alternatives, their discussion and renewed alternative development. To support this task, the optimization model formulated by Meyer with the aim of minimising total landed costs is used. In the second step, the ideal plan of the network structure is developed within the migration planning and adapted to the existing restrictions [35].

Through the gradual development of alternatives with consideration of the newly gained knowledge, Meyer presents an approach that provides iterative data collection, although it is not explicitly mentioned and elaborated in detail [24]. One main disadvantage of the model is that it is not known how the ideal planning is subsequently transferred into the real planning. Furthermore, the generation of multiple action alternatives with consideration of several target values is requested, but not further elaborated. [35] Moreover, the process model does not include the potentials of the current plant situation into the creation of alternatives.

Moser pursues the goal of robust migration paths and risk-efficient converters for production networks in a volatile business environment. The model consists of three phases. The first phase, which is called the configuration phase, consists of the formulation of the global production strategy and the definition of the modelling of network configurations. Based on the prioritization of differentiation factors, strategic network and location capabilities are derived and possible network resources for its realization are modelled. In the optimization phase, the cost-optimal migration strategy is then derived and it determines a robust migration path. For this purpose, a stochastic optimization model is used. Finally, the selection phase serves for the selection of risk-efficient converters with the aim of achieving the optimum level of adaptability for the network resources to be migrated [36].

\subsection{Evaluation Approaches}

Evaluation approaches belong to the MADM (Multiattribute Decision Making) field. The decision-making takes place in a discrete solution space between a countable numbers of alternatives [37]. Besides the consideration of process-related aspects, evaluation approaches include detailed analyses of network alternatives, e.g. using modelbased simulation approaches instead [24].

Merchiers provides an evaluation support for the design and selection of different site structure approaches. The focus lies on the quantitative evaluation of alternative actions in early phases of site structure planning. The application sets the restriction of an implicit to an explicit solution space. For supporting the solution process, a dynamic profitability calculation is used. With the goal of the cause-related recording of costs and payments, a distinction is made between the module level, site level and network level [38].

The approach of Merchiers offers a comprehensive overview of the relevant cost factors of the configuration of networks in the different areas of the company by dividing it into the module level, site level and network level. In the approach, the analysis does not take into account for example sensitivity or risk assessment to consider existing uncertainties, and nor does it use a multi-criteria target system [24]. The effort for building the cost model is very high and a selection of relevant costs according to the expenditure is not used [39].

The consideration of multidimensional uncertainties in the evaluation of networked production sites form the core of the work of Krebs. While quantitative uncertainties are mapped by using the risk analysis method, qualitative uncertainties are modelled by using the fuzzy set theory. The developed procedure for the evaluation of location alternatives consists of five iterative steps. Only monetary targets of the site selection are considered. All relevant influencing factors and uncertainties as well as their dependencies are to be depicted in a corresponding calculation model. By modelling the individual uncertainties and their dependencies by using the probability theory and the fuzzy evaluation network is then used to generate an uncertainty model set up. The link between the calculation and uncertainty model allows the monetary target value for each alternative to be determined by using the Monte Carlo simulation. For the final phase of the evaluation, various methods for the risk assessment and sensitivity analysis were presented [40]. The evaluation model by Krebs only focuses on the monetary targets of the site selection and it does not derive the targets from the corporate strategy.

\subsection{Findings \& Conclusion}

This chapter summarizes the findings of the literature analysis according to the derived requirements in the chapter before. One goal of this paper is to define the suitable models according to the defined requirements. Therefore, Fig. 6 shows the evaluation of the three introduced focuses of the models. The evaluation of the specific models was described in the previous chapter. As shown in Fig. 6, the mathematical optimization models have major deficits in an iterative process character as they just optimize an existing system to one specific goal. Furthermore, the integration of the impact of tactical/operational planning is not done, as the result of most optimization models is in just one optimal solution and it does not include the required changes on the tactical level. One further big disadvantage of mathematical optimization models is that finding optimal solutions is ambitious for reallife problems due to their complexity. The method can only be applied when the network is well-understood and can be described analytically [41].

Classical process models neglect the concrete determination and evaluation of network alternatives [32]. 
Additionally, process models overall lack in an iterative character during decision-making, as well as in the multiple usage by future changes.

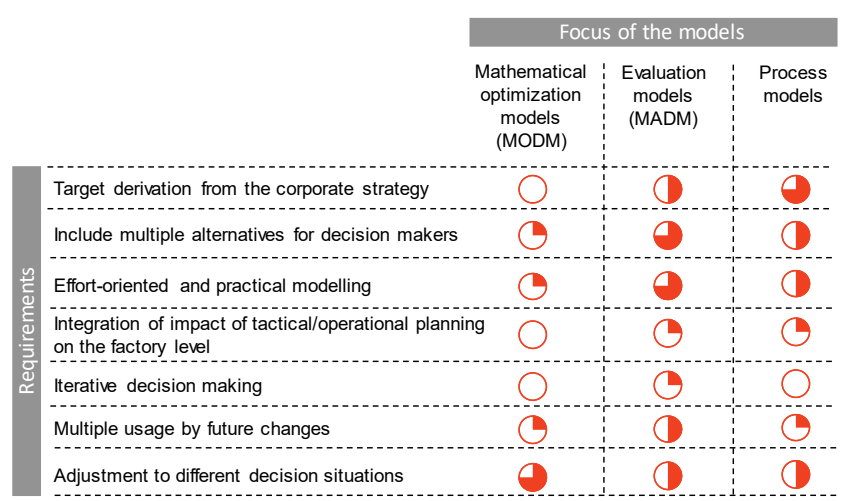

Figure 6 Derived findings from literature

In terms of the effort-oriented and practical modelling and the link to reality, MADM models and process models combined with discrete simulation seem to be a suitable solution for the configuration of production networks in an iterative way. They also include the tactical/operational impacts or potentials into the strategic decision-making process and they do not require such high effort for modelling as it is the case with mathematical optimization models.

Although the existing MADM models already meet certain defined requirements, the analysed models still do not provide the specific tools or process steps in terms of different model adjustments to different decision situations, iterative decision-making and the integration of the impacts of subsequent processes such as the factory planning into the strategic decision-making. To close the gap in literature and to meet the need from the industry, what is required is a process model which focuses on integrating the impact of tactical planning at the factory level into strategic decisionmaking in an iterative way. Therefore, the following phases are proposed to be included in a model for strategic production network planning: (1) target definition and data collection at the production network level, (2) variant creation for the defined strategic goals, (3) variant analysis and evaluation with simulation models, (4) integration of the tactical/operational view with the results of the factory planning process until a defined process step, and (5) iterative variant creation with a new information base of the pervious step.

\section{SUMMARY AND OUTLOOK}

In recent years, large and mid-sized companies have expanded their own production network due to strategic decisions regarding market development in emerging markets and cost factors in low-wage countries. These production networks grow historically and contain in most cases huge potential for optimization. Many companies are faced with huge challenges during the planning and structuring phase of production networks due to high task complexity. One main challenge, also described in literature, is the integration of interrelations between the network (strategic level) and the plant level (tactical/operational) during planning. The existing models for production network planning lack in the identified requirements such as integrating the factory level into strategic planning or in the iterative decision-making process. To counteract these challenges, a model with five defined phases was introduced, which integrates tactical impacts in an iterative way and supports managers during the ongoing process of the planning and adaption of production networks, triggered by different changes, and it reduces the risk of wrong decisionmaking in an effort-oriented and practical way.

Next steps will be a detailed design of the five phases, definition of the performance indicators for the comparison of the different variants and the evaluation of the model within an industrial company in the railway maintenance sector, which owns a historically grown network of over 15 sites.

\section{Notice}

The paper will be presented at the MOTSP $2020-$ International Conference Management of Technology - Step to Sustainable Production, which will take place from $30^{\text {th }}$ September $-2^{\text {nd }}$ October 2020 in Bol, island Brač (Croatia). The paper will not be published anywhere else.

\section{REFERENCES}

[1] Abele, E. (2008). Global production. A handbook for strategy and implementation. Springer, Berlin. https://doi.org/10.1007/978-3-540-71653-2

[2] Friedli, T., Lanza, G., Schuh, G. et al (2017). Active design of production networks. $Z W F, 112(5), 279-283$. https://doi.org/10.3139/104.111716

[3] Coe, N. M., Dicken, P., \& Hess, M. (2008). Global production networks: realizing the potential. Journal of Economic Geography, 8(3), 271-295. https://doi.org/10.1093/jeg/lbn002

[4] https://www.bcg.com/de-at/publications/2020/threegovernment-priorities-for-rebuilding-post-covid.aspx (18.06.2020)

[5] Wiendahl, H., Reichardt, J., \& Nyhuis, P. (2009). Handbuch Fabrikplanung. Konzept, Gestaltung und Umsetzung wandlungsfähiger Produktionsstätten, Carl Hanser Verlag, München, Wien. https://doi.org/10.3139/9783446423237

[6] Schuh, G. et al. (2018). An Approach for Rolling Planning of Migration in Production Networks. Proceedings of the 2018 IEEE, IEEM. https://doi.org/10.1109/IEEM.2018.8607294

[7] Váncza, J. (2016). Production Networks. Laperrière L, Reinhart G. (eds) CIRP encyclopedia of production engineering. Springer, Berlin. https://doi.org/10.1007/978-3-642-35950-7_16829-1

[8] Justus, A. (2009). Management globaler Produktionsnetzwerke - Dimensionen und Handlungsfelder für die Gestaltung, Lenkung und Entwicklung; Kovac, Hamburg, p. 24f

[9] Götze, U. (1997). Standort, Standortkosten, Standortmodelle, Standortplanung, Standortstruktur, Standortstrukturcontrolling, Standortstrukturkontrolle, Standortstrukturplanung, einzelwirtschaftliche Standorttheorien, Standortverteilung. In: Bloech, J./Ihde, G. B. (Hrsg.): Vahlens großes Logistiklexikon; Vahlen, München, 981-1005.

[10] Hermann, M., Pentek, T., \& Otto, B. (2016). Design Principles for Industrie 4.0 Scenarios. The $49^{\text {th }}$ Hawaii International Conference on System Sciences (HICSS), Koloa, HI, 39283937. https://doi.org/10.1109/HICSS.2016.488 
[11] Rudberg, M. \& Olhager, J. (2003). Manufacturing networks and supply chains: An operations strategy perspective. Omega, 31, 29-39. https://doi.org/10.1016/S0305-0483(02)00063-4

[12] Jacob, F. (2006). Quantitative Optimierung dynamischer Produktionsnetzwerke. TU Darmstadt (2005). Darmstädter Forschungsberichte für Konstruktin und Fertigung. Aachen: Shaker.

[13] Pümpin, von C. \& Amann, W. (2005). SEP. Strategische Erfolgspositionen: Kernkompetenzen aufbauen und umsetzen, (Deutsch) Taschenbuch, 1. Aufl., Haupt Verlag, Bern, p. 136.

[14] Thomas, S. 2013. Produktionsnetzwerksysteme: Ein Weg zu effizienten Produktionsnetzwerken. Diss. Universtität St. Gallen, p. 53.

[15] Miltenburg, J. (2009). Setting manufacturing strategy for a company's international manufacturing network. International Journal of Production Research, 47(22), 6179-6203. https://doi.org/10.1080/00207540802126629

[16] Friedli, T., Thomas, S., \& Mundt, A. (2013). Management globaler Produktionsnetzwerke - Strategie, Konfiguration, Koordination, Hanser, München. https://doi.org/10.3139/9783446437661

[17] Pawellek, G. (2008). Ganzheitliche Fabrikplanung: Grundlagen, Vorgehensweise, EDV-Unterstützung, SpringerVerlag, Heidelberg. https://doi.org/10.1007/978-3-540-78403-6

[18] Ferdows K. (2014). Relating the Firm's Global Production Network to Its Strategy. In: Johansen, J., Farooq, S., et al. (Hrsg.): International Operations Networks, Springer, London, 1-11. https://doi.org/10.1007/978-1-4471-5646-8_1

[19] Laux, H. et al. (2012). Entscheidungstheorie. 8. Aufl. 2012. Korr. Nachdruck 2012. Berlin, Heidelberg: Springer (SpringerLehrbuch). https://doi.org/10.1007/978-3-642-23511-5

[20] Taylor, J. (2012). Decision management systems. A practical guide to using business rules and predictive analytics. Upper Saddle River, N.J.: IBM Press/Pearson. (78)

[21] Hitomi, K. (1996). Manufacturing Systems Engineering: A Unified Approach to Manufacturing Technology, Production Management and Industrial Economics. London: Taylor \& Francis, (39).

[22] Maurer, A., Spindelndreier, D., \& Türpitz, A. (2009). The power of cost transparency: Finding hidden value in manufacturing networks. Hrsg. von The Boston Consulting Group.

[23] Schuh, G., Potente, T., Kupke, D., Varandani, R. M., \& Hausberg, C. (2019). An Evolutionary Approach for Global Production Network Optimisation. Procedia CIRP, 3(2012), 382-387. https://doi.org/10.1016/j.procir.2012.07.066

[24] Sager, B. (2019). Konfiguration globaler Produktionsnetzwerke, TU München.

[25] Spetzler, C. S. (2016). Decision Quality: Value Creation from Better Business Decisions, p. 1. John Wiley \& Sons Inc, Hoboken.

[26] Adam, D. (1993). Planung und Entscheidung: Modelle - Ziele - Methoden. 3. Aufl. Wiesbaden: Gabler. https://doi.org/10.1007/978-3-322-89347-5

[27] Ferdows K. (2018). Keeping up with growing complexity of managing global operations. Int J Prod Operat Manag, 38(2), 390-402. https://doi.org/10.1108//JOPM-01-2017-0019

[28] Gözer, P. et al. (2013). Taktische Planung in Produktionsnetzwerken - Herausforderungen für Zulieferer mit großer Produktvielfalt und hoher Wertschöpfung, ZWF, Hanser Verlag. https://doi.org/10.3139/104.110938

[29] Grundig, C. G. (2018). Fabrikplanung - Planungssystematik Methoden-Anwendungen, Carl Hanser Verlag. https://doi.org/10.3139/9783446454019

[30] Wiendahl, H.-P., ElMaraghy, H. A., \& Nyhuis, P. (2007). Changeable manufacturing - classification, design and operation. CIRP Ann, 56(2), 783-809. https://doi.org/10.1016/j.cirp.2007.10.003

[31] Cheng, Y. \& Johansen, J. (2015). International manufacturing network: Past, present, and future. International Journal of Operations \& Production Management, 35. 392-429. https://doi.org/10.1108//JOPM-03-2013-0146

[32] Ernst, J. (2012). Methode zur Ermittlung von Standortstrukturalternativen in Maschinenbauunternehmen. Diss. TU Darmstadt (2012). Schriftenreihe des PTW: "Innovation Fertigungstechnik". Aachen: Shaker

[33] Christodoulou, P., Fleet, D., Phaal, R., Probert, D., Hanson, P., \& Shi, Y. (2007). Making the right things in the right places: A structured approach to developing and exploiting 'manufacturing footprint' strategy. Cambridge: University of Cambridge Institute for Manufacturing.

[34] Lanza, G. \& Moser, R. (2014). Multi-objective optimization of global manufacturing networks taking into account multidimensional uncertainty. CIRP Annals - Manufacturing Technology, 63(1), 397-400. https://doi.org/10.1016/j.cirp.2014.03.116

[35] Meyer, T. (2006). Globale Produktionsnetzwerke: Ein Modell zur kostenoptimierten Standortwahl. Darmstädter Forschungsberichte für Konstruktion und Fertigung. Aachen: Shaker.

[36] Moser, E. (2017). Migrationsplanung globaler Produktionsnetzwerke: Bestimmung robuster Migrationspfade und risikoeffizienter Wandlungsbefähiger. Forschungsberichte aus dem WBK, Institut für Produktionstechnik, Karlsruher Institut für Technologie (KIT) Bd. 210. Aachen: Shaker.

[37] Zimmermann, H.-J. \& Gutsche, L. (1991). Multi-Criteria Analyse: Einführung in die Theorie der Entscheidungen bei Mehrfachzielsetzungen. Heidelberger Lehrtexte Wirtschaftswissenschaften. Berlin, Heidelberg: Springer. https://doi.org/10.1007/978-3-642-58198-4

[38] Merchiers, A. (2008). Bewertung globaler Standortstrukturalternativen im Maschinenbau. Ergebnisse aus der Produktionstechnik. Aachen: Apprimus.

[39] Prote, J. (2018). Verursachungsgerechte Bewertung von Standortalternativen in Produktionsnetzwerken. Ergebnisse aus der Produktionsntechnik. Aachen: Apprimus.

[40] Krebs, P. (2011). Bewertung vernetzter Produktionsstandorte unter Berücksichtigung multidimensionaler Unsicherheiten. Forschungsberichte IWB 255. München: Utz. 2012

[41] Stecca, G., Lanza, G., \& Peters, S. (2014) Optimization in Manufacturing. In: The International Academy for Production Engineering, Laperrière L., Reinhart G. (eds) CIRP Encyclopedia of Production Engineering. Springer, Berlin, Heidelberg, 929-932. https://doi.org/10.1007/978-3-642-20617-7_6565

\section{Authors' contacts:}

Elias Auberger, Dipl. Ing.

(Corresponding author)

Institute of Innovation and Industrial Management,

Graz University of Technology,

Kopernikusgasse 24/II, 8010 Graz, Austria

+43 316873 7792, elias.auberger@tugraz.at

Christian Ramsauer, Univ. Prof. Dipl. Ing. Dr. Techn. Institute of Innovation and Industrial Management, Graz University of Technology,

Kopernikusgasse 24/II, 8010 Graz, Austria

+43 316873 7290, christian.ramsauer@tugraz.at 